\title{
Diversificació d'activitats per treballar el territori a través de l'aprenentatge de la llengua catalana com a segona llengua en el context del sistema educatiu francès al Principat d'Andorra
}

\author{
Alexandra Monné \\ Universitat d'Andorra \\ amonne@uda.ad
}

Rebut: 2 de juny de 2021

Acceptat: 9 d'agost de 2021

\section{Resum}

L'experiència didàctica Dossier de parròquia, portada a terme a l'assignatura Didàctica de les Llengües II del bàtxelor en Ciències de l'Educació de la Universitat d'Andorra, mostra com l'aprenentatge a través del treball per projectes pot mobilitzar els coneixements i les competències lingüístiques i culturals de la formació inicial de mestres. Els estudiants universitaris, a partir d'un treball previ d'anàlisi de materials educatius, dissenyen una proposta didàctica en forma de dossier per a alumnes d'últim curs d'educació primària dels sistema educatiu francès.

\section{Context}

L'experiència didàctica que presentem a continuació és una activitat que es va dur a terme amb els estudiants del bàtxelor de Ciències de l'Educació de la Universitat d'Andorra (UdA). Per tal d'activar nous esquemes de coneixement, així com habilitats interculturals i multilingüístiques, es va dissenyar el Dossier de parròquia com a recurs didàctic que mobilitza coneixements sobre la cultura andorrana i la llengua catalana. L'experiència se centra en les àrees de les ciències socials i de les llengües, respectivament, i es fonamenta en tres pilars clau: el coneixement del patrimoni, l'aprenentatge de la llengua catalana com a segona llengua i l'aprenentatge a través del treball per projectes. Tenint en compte això, demanàvem als estudiants universitaris que dissenyessin un dossier pensant en alumnes de l'últim curs d'educació primària del sistema educatiu francès i que, per tant, aprenen català com a segona llengua. ${ }^{1}$

1 Les llengües obligatòries del sistema educatiu francès a Andorra en l'etapa d'educació primària són el francès i el català. El francès és llengua vehicular i el català, que és la llengua nacional, s'ensenya com a segona llengua a l'assignatura obligatòria de llengua i medi durant tres hores a la setmana a través del programa estatal de formació andorrana. 
La importància d'aprofundir en el coneixement del patrimoni cultural d'Andorra en el context de la formació inicial de mestres permet reflexionar a nivell psicopedagògic i didàctic sobre les actituds existents cap a la pròpia cultura. El coneixement del patrimoni implica la introducció d'aspectes com la convivència, la valoració i la validació de l'altre, així com la interacció a través del mutu reconeixement (Sabariego, 2003).

\section{Objectius}

Els objectius generals d'aquesta experiència se centren a (1) impulsar l'aprenentatge de la llengua catalana com a segona llengua, (2) conèixer el patrimoni a les aules tant universitàries com escolars i (3) dissenyar un recurs educatiu sobre la cultura andorrana en llengua catalana dirigit a infants d'edats de tercer cicle de primària a través del qual s'activen les competències culturals i lingüístiques. Aquests objectius generals es concreten en els següents objectius específics:

1. Crear un material educatiu aplicat que permeti un apropament entrel'escola i la universitat, per a la construcció de coneixement al voltant de la llengua i cultura pròpia d'Andorra.

2. Incrementar la competència comunicativa dels futurs mestres en l'aplicació de la didàctica en llengua catalana.

3. Incorporar aspectes de la cultura andorrana en els seus treballs pràctics i programacions.

4. Promoure la llengua oficial i cultura d'Andorra a l'aula.

\section{Competències}

A la taula 1 queden reflectides les competències específiques que l'assignatura Didàctica de les Llengües II pretén aconseguir, així com el nivell o grau de desenvolupament de cada competència en referència al pla d'estudis del bàtxelor en Ciències de l'Educació (BCE) de la Universitat d'Andorra. La numeració correspon a les competències específiques d'aquesta titulació i que es tenen en compte en aquest projecte. És així que trobem, per exemple, BCE1 BCE11 quan alguna d'aquestes competències inclou més d'un aspecte a destacar. D'altra banda, cada competència té tres nivells d'assoliment: el nivell 1 equivaldria a un nivell superficial; el 2, a un nivell mitjà, i el nivell 3, a un de superior. Aquest 1, 2, o 3 el determina el pla d'estudis en funció del curs en què s'ofereix l'assignatura. Quan es diu que s'assoleix la competència a un nivell 1 , és perquè hi ha altres assignatures que també contemplen la mateixa competència però que l'eleven a un nivell superior. I quan la competència s'assoleix a un nivell 3 és perquè les altres assignatures l'han desenvolupat a nivells inferiors. Vegem tot el que hem dit fins ara, a la taula 1.

Taula 1. Taula de competències específiques del bàtxelor en Ciències de l'Educació de l'UdA per a l'assignatura i nivells de desenvolupament.

\begin{tabular}{|l|l|l|l|l|}
\hline Assignatura & Didàctica de les llengües II & & $\begin{array}{l}\text { 2 Analitza, classi- } \\
\text { Grau de desenvolupament de la competèn- } \\
\text { cia }\end{array}$ & $\begin{array}{l}\text { 1 Identifica, co- } \\
\text { neix i comprèn } \\
\text { avalua i dissenya } \\
\text { nentatge }\end{array}$ \\
\hline Competències específiques & \\
\hline BCE1 Comunica en un context multilingüe & $\begin{array}{l}\text { fica } \\
\text { gomina l'ús de la llen- }\end{array}$ & & 3 \\
\hline BCE11 & $\begin{array}{l}\text { Fomenta els trets multi- } \\
\text { lingües }\end{array}$ & & 3 \\
\hline BCE12 & & & \\
\hline
\end{tabular}




\begin{tabular}{|c|c|c|c|c|}
\hline \multicolumn{5}{|c|}{ BCE2 Comprèn els continguts i la seva validesa } \\
\hline BCE21 & $\begin{array}{l}\text { Comprèn els continguts } \\
\text { curriculars }\end{array}$ & & 2 & \\
\hline BCE22 & $\begin{array}{l}\text { Comprèn la didàctica } \\
\text { específica }\end{array}$ & & & 3 \\
\hline \multicolumn{5}{|c|}{ BCE3 Planifica, dissenya i du a terme processos d'e/a } \\
\hline BCE31 & $\begin{array}{l}\text { Planifica i dissenya } \\
\text { processos d'e/a }\end{array}$ & & & 3 \\
\hline BCE32 & $\begin{array}{l}\text { Du a terme processos } \\
\text { d'e/a }\end{array}$ & & & 3 \\
\hline \multicolumn{5}{|c|}{ BCE4 Planifica, dissenya i du a terme processos d'atenció a la diversitat } \\
\hline BCE41 & $\begin{array}{l}\text { Planifica intervencions } \\
\text { adaptades }\end{array}$ & & 2 & \\
\hline BCE42 & $\begin{array}{l}\text { Gestiona l'heterogeneï- } \\
\text { tat del grup }\end{array}$ & & 2 & \\
\hline \multicolumn{5}{|c|}{ BCE8 Implica els alumnes en el seu procés d'e/a } \\
\hline BCE81 & $\begin{array}{l}\text { Implica els alumnes en } \\
\text { el seu procés d'e/a }\end{array}$ & 1 & & \\
\hline \multicolumn{5}{|c|}{ BCE11 Garanteix la progressió en els aprenentatges } \\
\hline BCE111 & $\begin{array}{l}\text { Regula els processos } \\
\text { d'aprenentatge }\end{array}$ & & 2 & \\
\hline
\end{tabular}

A la taula 2 es presenten les competències que l'experiència del Dossier de parròquia mobilitza, que coincideixen amb les del bàtxelor.

Taula 2. Taula de competències mobilitzades per l'experiència educativa Dossier de parròquia

\begin{tabular}{|l|l|}
\hline \multicolumn{2}{|l|}{ Competències específiques } \\
\hline BCE11 & Domina l'ús de la llengua \\
\hline BCE12 & Fomenta els trets multilingües \\
\hline BCE21 & Comprèn els continguts curriculars \\
\hline BCE22 & Comprèn la didàctica específica \\
\hline BCE31 & Planifica i dissenya processos d'e/a \\
\hline BCE32 & Duu a terme processos d'e/a \\
\hline BCE41 & Planifica intervencions adaptades \\
\hline BCE42 & Gestiona l'heterogeneïtat del grup \\
\hline BCE81 & Implica els alumnes en el seu procés d'e/a \\
\hline BCE111 & Regula els processos d'aprenentatge \\
\hline
\end{tabular}

\section{Metodologia}

Aquesta experiència es basa en la metodologia de l'aprenentatge basat en projectes (ABP) com una proposta estratègica en la qual l'estudiant deixa de ser un subjecte passiu per ser l'agent actiu del seu aprenentatge (Dewey, 1967). En el cas que estem presentant, van participarhi deu estudiants universitaris de segon curs del BCE, que havien de dissenyar un dossier amb activitats per a 42 escolars de l'escola francesa de primària d'Ordino a la classe de CM2 (equivalent a 5 è de primària). 
Durant l'elaboració del Dossier de parròquia, es van establir un seguit de fases que responen als principis constructivistes següents:

- Introduir el projecte per motivar i convidar l'estudiant a resoldre un repte educatiu.

- Informar els estudiants sobre les competències a desenvolupar i les expectatives d'aprenentatge.

- Organitzar els equips de treball, planificar les tasques i consensuar un calendari.

- Tutoritzar i guiar el treball dels estudiants.

- Presentar i defensar les propostes de cada estudiant.

- Reflexionar i avaluar conjuntament: fomentar l'autoavaluació, l'avaluació entre iguals i l'avaluació del professorat.

\section{Experiència Dossier de parròquia}

L'objectiu del Dossier de parròquia és fer una unitat didàctica sobre cada parròquia d'Andorra. L'experiència integra un conjunt de set dossiers: un per a cada parròquia, ${ }^{2}$ destinat a infants d'11 anys del sistema educatiu francès.

Cadascun d'aquests dossiers inclou entre 50 i 100 activitats que permeten treballar de manera lúdica i globalitzada continguts relacionats amb cada parròquia en diferents àmbits de l'àrea de medi social. Els estudiants s'han inspirat en el joc del Trivial per crear activitats d'aprenentatge, que promouen habilitats de tipus mecànic, analític, sintètic, creatives, comunicatives, interdisciplinàries, de sortida i de recerca, i d'avaluació, que activen habilitats de coneixements previs, reforç, aprofundiment i de síntesi final. La proposta es fa en llengua catalana per reforçar les necessitats lingüístiques del grup classe. Per tal que es puguin posar en pràctica les activitats a les escoles, les activitats van acompanyades d'un manual explicatiu amb instruccions d'ús per als mestres i jugadors, així com el material necessari per poder resoldre cada activitat.

El Dossier de parròquia és un recurs educatiu amb una gran varietat de temàtiques per treballar continguts de diferents àmbits:

1. llengua (llengua oficial i les més parlades, etimologia dels topònims, gentilicis, llegendes, dites, refranys);

2. elements de l'espai i territori (edificis emblemàtics, museus i cases pairals);

3. història (prehistòria, Pariatges, Consell de la Terra, Manual Digest, Politar andorrà, dates històriques);

4. societat (oficis antics);

5. economia (sectors econòmics);

6. cultura (festes tradicionals, elements de patrimoni, falles);

7. política (poders polítics, cònsols, consellers, caps de govern, coprínceps, departaments i àrees del Comú);

8. institucions (Batllia, Casa de la Vall, Consell, Comú, Govern);

9. geografia (situació al mapa, pics, refugis, valls, ports de muntanya, parcs naturals, pobles per parròquia, coordenades, carrers, rutes, itineraris, codis postals, indrets);

10. hidrografia (llacs, fonts i rius);

11. flora (flors, vegetació i arbusts);

12. fauna (animals);

2 Es van tractar set parròquies: Andorra la Vella, La Massana, Ordino, Encamp, Canillo, Sant Julià i Escaldes Engordany. 
13. gastronomia (plats típics);

14. art (esglésies, campanars, ponts, pintures, frescos, escultures, arquitectura, castells, balmes);

15. música (himne, balls típics);

16. demografia i estadística (nacionalitat, edat, gènere, parròquia, llengua, natalitat, mortalitat, gentilicis);

17. simbologia (escut, bandera, lema),

18. i personatges cèlebres, patrons i mites.

El dossier conté divuit temàtiques i cada una equival a una parcel-la del coneixement del territori andorrà. El resultat final és un dossier amb activitats d'aprenentatge variades que impliquen diferents habilitats com les següents:

- activitats mecàniques (encerclar, diferenciar de veritable o fals, unir punts, fer recorreguts, relacionar, identificar, localitzar, enumerar, desxifrar jeroglífics, simetries)

- activitats d'anàlisi (sopes de lletres, penjats, omplir buits, trobar les diferències)

- activitats de síntesi (resumir, sintetitzar)

- activitats creatives (fer cal-ligrames, escriure poesies, pintar, dibuixar, fer murals, fotografiar, fer maquetes)

- activitats comunicatives (mots encreuats, anomenar, cantar, narrar, descriure, contar, endevinar, llegir, escriure, dramatitzar, aprendre dites i refranys populars, fer exposicions orals, debats, receptes, escriure cartes, exposar l'opinió, ballar)

- activitats interdisciplinàries (elaborar gràfics i piràmides de població, fer frisos cronològics, interpretar plànols)

- activitats de sortida (fer sortides in situ, orientar-se)

- activitats de recerca (anar als arxius, enquestar, entrevistar)

\section{Avaluació}

A la taula 3 es presenten els indicadors d'avaluació emprats per a cada Dossier de parròquia. Els indicadors que s'han considerat per avaluar l'experiència permeten activar els diferents aspectes que es tenen en compte per mobilitzar les competències específiques tot respectant les fases de la metodologia d'ABP, que posiciona l'estudiant al centre de la seva formació. D'aquesta manera, se li genera interès per investigar i trobar solucions a un problema significatiu i contextualitzat en la realitat permetent avaluar-se i regular el seu propi aprenentatge (Kilpatrick, 1918). 
Taula 3. Taula d'indicadors d'avaluació del Dossier de parròquies

\begin{tabular}{|c|c|c|c|c|c|c|c|}
\hline $\begin{array}{l}\text { Nom } \\
\text { de la } \\
\text { parròquia }\end{array}$ & Andorra & $\begin{array}{l}\text { La } \\
\text { Massana }\end{array}$ & Ordino & Encamp & Canillo & $\begin{array}{l}\text { Sant } \\
\text { Julià }\end{array}$ & $\begin{array}{l}\text { Escaldes } \\
\text { Engor- } \\
\text { dany }\end{array}$ \\
\hline \multirow{18}{*}{$\begin{array}{l}\text { A. Àmbits } \\
\text { temàtics } \\
\text { (Total 18) }\end{array}$} & Llengua & & & & & & \\
\hline & Espai i territori & & & & & & \\
\hline & Història & & & & & & \\
\hline & Societat & & & & & & \\
\hline & Economia & & & & & & \\
\hline & Cultura & & & & & & \\
\hline & Política & & & & & & \\
\hline & Institucions & & & & & & \\
\hline & Geografia & & & & & & \\
\hline & Hidrografia & & & & & & \\
\hline & Flora & & & & & & \\
\hline & Fauna & & & & & & \\
\hline & Gastronomia & & & & & & \\
\hline & Art & & & & & & \\
\hline & Música & & & & & & \\
\hline & $\begin{array}{l}\text { Demografia i } \\
\text { estadística }\end{array}$ & & & & & & \\
\hline & Simbologia & & & & & & \\
\hline & $\begin{array}{l}\text { Personatges, } \\
\text { patrons i mites }\end{array}$ & & & & & & \\
\hline \multirow[t]{13}{*}{$\begin{array}{l}\text { B. Activitats } \\
\text { (Total 12) }\end{array}$} & Tipologia & Tipus & $\begin{array}{l}\text { Nombre } \\
\text { d'activitats }\end{array}$ & Observac & ions & & \\
\hline & \multirow{8}{*}{$\begin{array}{l}\text { Aprenentatge } \\
\text { (Total 8) }\end{array}$} & Anàlisi & & & & & \\
\hline & & Síntesi & & & & & \\
\hline & & Mecànica & & & & & \\
\hline & & Sortida & & & & & \\
\hline & & $\begin{array}{l}\text { Interdisci- } \\
\text { plinari }\end{array}$ & & & & & \\
\hline & & Recerca & & & & & \\
\hline & & $\begin{array}{l}\text { Comunica- } \\
\text { tiva }\end{array}$ & & & & & \\
\hline & & Creativa & & & & & \\
\hline & \multirow[t]{4}{*}{$\begin{array}{l}\text { Avaluació } \\
\text { (Total 4) }\end{array}$} & $\begin{array}{l}\text { Coneixe- } \\
\text { ments } \\
\text { previs }\end{array}$ & & & & & \\
\hline & & Reforç & & & & & \\
\hline & & Ampliació & & & & & \\
\hline & & Final & & & & & \\
\hline
\end{tabular}




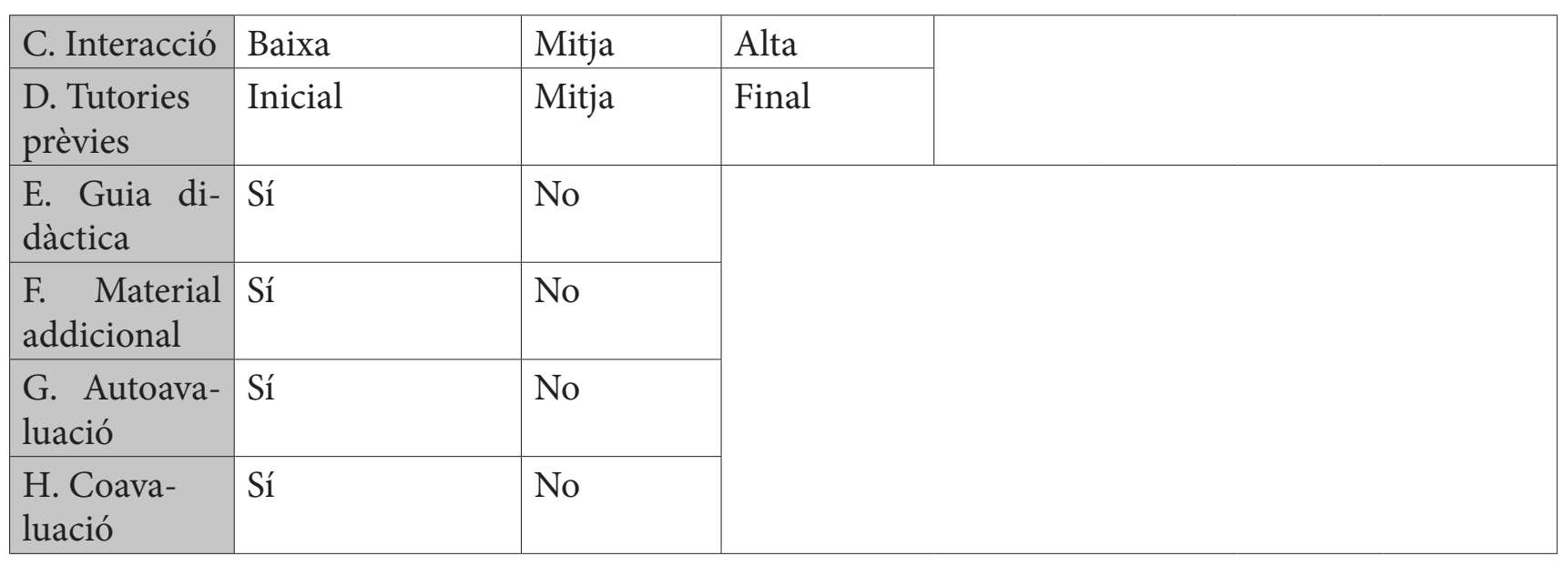

A partir dels indicadors d'avaluació del Dossier de parròquia, que serveixen com a guia per saber si les propostes educatives fetes s'adeqüen als objectius i competències, s'estructuren els resultats d'aprenentatge. Per això, s'ha dissenyat una rúbrica per establir uns resultats d'aprenentatge i els nivells d'assoliment inspirada en la Guia per avaluar el disseny de les activitats educatives patrimonials del Departament de Cultura de la Generalitat de Catalunya, tal com es mostra a la taula 4. Per tant, per a l'avaluació s'han desplegat una sèrie d'eines, com són la taula d'indicadors d'avaluació per a cada dossier didàctic i els resultats d'aprenentatge des del binomi patrimoni cultural i llengua catalana.

Taula 4. Rúbrica de resultats d'aprenentatge

\begin{tabular}{|c|c|c|c|}
\hline Grau d'assoliment & Nivell baix (1) & Nivell mig (2) & Nivell alt (3) \\
\hline $\begin{array}{l}\text { El material permet la } \\
\text { interacció amb l'entorn }\end{array}$ & $\begin{array}{l}\text { L'activitat educativa és } \\
\text { tancada i no promou les } \\
\text { aportacions i raonaments } \\
\text { de l'alumnat }\end{array}$ & $\begin{array}{l}\text { L'activitat educativa } \\
\text { permet que l'alumnat } \\
\text { faci observacions i } \\
\text { raonaments, però no els } \\
\text { té en compte a l'hora de } \\
\text { desenvolupar l'activitat }\end{array}$ & $\begin{array}{l}\text { L'activitat educativa } \\
\text { té un plantejament } \\
\text { estimulant i obert i } \\
\text { s'enriqueix a partir } \\
\text { de les observacions i } \\
\text { aportacions de l'alum- } \\
\text { nat }\end{array}$ \\
\hline $\begin{array}{l}\text { Fomenta la competèn- } \\
\text { cia comunicativa en } \\
\text { llengua catalana }\end{array}$ & $\begin{array}{l}\text { L'activitat educativa no } \\
\text { té present ni actituds ni } \\
\text { valors de tipus lingüístic } \\
\text { en el disseny de l'activitat }\end{array}$ & $\begin{array}{l}\text { L'activitat educativa in- } \\
\text { corpora algunes actituds } \\
\text { i valors de tipus lingüís- } \\
\text { tic, però no els explicita } \\
\text { en el disseny de l'activitat }\end{array}$ & $\begin{array}{l}\text { L'activitat educativa } \\
\text { fomenta actituds i } \\
\text { incorpora valors de } \\
\text { tipus lingüístic com } \\
\text { a element intrínsec al } \\
\text { disseny de l'activitat }\end{array}$ \\
\hline $\begin{array}{l}\text { Incorpora aspectes del } \\
\text { patrimoni andorrà }\end{array}$ & $\begin{array}{l}\text { No es produeixen con- } \\
\text { nexions entre situacions } \\
\text { reals conegudes per } \\
\text { l'alumnat i els elements } \\
\text { patrimonials }\end{array}$ & $\begin{array}{l}\text { Es produeixen conne- } \\
\text { xions entre situacions } \\
\text { reals conegudes per } \\
\text { l'alumnat i elements pa- } \\
\text { trimonials en moments } \\
\text { molt puntuals de l'activi- } \\
\text { tat educativa }\end{array}$ & $\begin{array}{l}\text { Es produeixen conne- } \\
\text { xions entre els ele- } \\
\text { ments patrimonials i } \\
\text { les situacions reals co- } \\
\text { negudes per l'alumnat } \\
\text { al llarg de de l'activitat } \\
\text { educativa }\end{array}$ \\
\hline
\end{tabular}




\begin{tabular}{|c|c|c|c|}
\hline $\begin{array}{l}\text { Promou la llengua } \\
\text { catalana i la cultura } \\
\text { andorrana }\end{array}$ & $\begin{array}{l}\text { L'activitat educativa no } \\
\text { utilitza mai elements de } \\
\text { la cultura andorrana ni } \\
\text { de la llengua catalana per } \\
\text { presentar un discurs pe- } \\
\text { dagògic coherent amb els } \\
\text { objectius d'aprenentatge }\end{array}$ & $\begin{array}{l}\text { Només ocasionalment } \\
\text { l'activitat educativa } \\
\text { utilitza alguns elements } \\
\text { de la cultura andorrana i } \\
\text { de la llengua catalana per } \\
\text { presentar un discurs pe- } \\
\text { dagògic coherent amb els } \\
\text { objectius d'aprenentatge }\end{array}$ & $\begin{array}{l}\text { L'activitat educativa } \\
\text { relaciona els elements } \\
\text { de la cultura ando- } \\
\text { rrana i de la llengua } \\
\text { catalana per presentar } \\
\text { un discurs pedagògic } \\
\text { coherent amb els ob- } \\
\text { jectius d'aprenentatge }\end{array}$ \\
\hline
\end{tabular}

\section{Conclusions}

En el desenvolupament de les sessions a l'escola, els estudiants universitaris van vehicular els seus dossiers en llengua catalana, ja que a l'escola francesa el català es treballa com a segona llengua. Prèviament, els estudiants ja coneixien els plantejaments lingüístics de l'àrea de formació andorrana d'aquesta escola i per tant van poder incorporar-los en els seus dissenys.

Projectes col-laboratius d'aquest tipus donen sentit a la metodologia d'aprendre a aprendre, tot engrescant les institucions escolars i els diferents agents implicats, com ara els mestres i alumnes a l'escola, i els professors i estudiants a la universitat, que fan que l'ensenyança es posi al servei de l'aprenentatge i es doni un procés d'enriquiment mutu.

Aquesta experiència se situa en la línia de donar resposta a les possibles necessitats formatives dels futurs professionals i té l'objectiu d'establir ponts entre l'escola i la universitat. A més, planteja un treball interdisciplinari, tant de la llengua catalana com del patrimoni andorrà, per poder viure en societat d'una manera més democràtica i sostenible (Consell d'Europa, 2018).

\section{Referències}

Consell d'Europa. (2018). Reference framework of competences for democratic culture

- Volume 1: Context, concepts and model. https://rm.coe.int/prems-008318-gbr-2508reference-framework-of-competences-vol-1-8573-co/16807bc66c

Dewey, J. (1967). Experiencia y educación. Losada.

Generalitat de Catalunya. (2018). Departament de Cultura. Guia per avaluar el disseny de les activitats educatives patrimonials. Museus 2030. https://cultura.gencat.cat/web/.content/ dgpc/museus/08.recursos/publicacions/quaderns/02 Guia-avaluar-disseny-activitatseducatives-patrimonials.pdf

Kilpatrick, W. H. (1918). The project method. The use of the purposeful act in the educative process. Teachers College Bulletin. Tenth Series 3(12). Teachers College, Columbia University.

Sabariego, M. (2003). La formación del profesorado en educación intercultural. Temps d'Educació, 27, 33-52. http://www.raco.cat/index.php/TempsEducacio/article/view/126376 